\title{
Cancer comes under scrutiny in fresh genomics initiative
}

ثे Jonathan Knight, San Francisco

Genome researchers are planning an ambitious project to catalogue all the changes in gene activity associated with any type of cancer.

Organizers of the project, dubbed the International Genomics Consortium (IGC), say that ultimately it will collect gene expression information on a wide variety of diseases.

But some researchers fear that the project will duplicate existing efforts. And they worry that it might impose a single standard at too early a stage in the development of the DNA chip technology used to gather information on gene activity.

Biomedical researchers are increasingly dependent on DNA chips, also known as microarrays, because they can monitor changes in the expression of thousands of genes at once (see News Feature, page 860). Cancer researchers, for example, use chips to spot abnormal gene activity in tumours and so identify possible drug targets.

The project's $\$ 45$ million cost would be paid by the manufacturers of microarrays and associated technologies, but all data would be publicly available without restriction, says organizer Andy Baxevanis, director of computational genomics at the National Human Genome Research Institute (NHGRI) in Bethesda, Maryland.

Although both Baxevanis and co-organizer Jeff Trent are NHGRI researchers, they say that the project can proceed without federal support. They are currently negotiating with potential academic partners and industrial sponsors. Although no institution has officially signed up yet, dozens have expressed interest, Baxevanis says, including several in Europe.

In its first phase, the IGC would seek to assemble microarray data on 10,000 tumour samples from cancer centres worldwide by the middle of next year.

The IGC database would link the tumour gene profiles with anonymous clinical data on the patient. This would give scientists a quick way to see if a gene activated in breast cancer, for example, is also activated in other types of cancer. And oncologists would have immediate access to clinical records of patients with tumours that genetically match those of their own patients.

Rather than compiling existing gene expression data, the IGC would create its own, so that it could all be properly integrated into one database. Currently, different laboratories use different microarrays with different sets of genes, making database integration problematic (see page 851 ).

The organizers say they intend to work

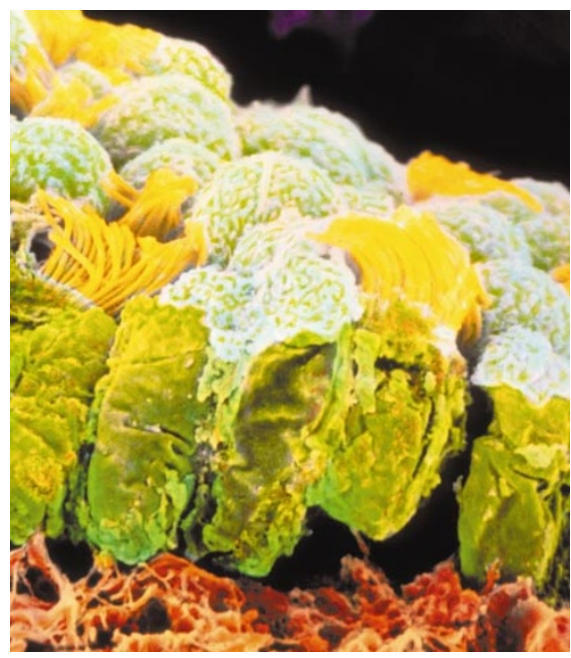

Growing up: the chips are down for tumours, with plans for a database of the genes behind cancer.

with DNA chip companies such as Affymetrix and Agilent Technologies, both of northern California, to develop one or two new standardized microarrays. Each participating institution would use the same standard chips under the supervision of IGC representatives who would ensure that all samples are treated the same way.

But some cancer researchers fear that the proposed project would merely duplicate their existing efforts. Samir Hanash, whose lab at the University of Michigan is one of about 20 funded by the National Cancer Institute to do expression profiling of cancer, says it would be better to combine all microarray data in a single location, rather than creating a separate database.

The more experiments are compared, the easier it will be to draw meaningful conclusions about the genes involved in cancer, he says. Hanash fears that the new collaboration will divide the available information between existing databases and the new one to be created. "There is a danger the effort will be diluted," he says.

Additionally, Hanash suggests, it may be too early to decide on the right gene-profiling standards. DNA chips measure the levels of messenger RNA, the direct product of genes, but proteins may be a better measure of gene activity, and could potentially be studied directly by new technologies. "Maybe microarrays are in fashion today but they still represent just one technology platform," he says.

But Baxevanis argues that establishing a standard for DNA chips now is the best way forward. "One reason expression databases have difficulty getting off the ground is they are comparing apples and oranges," he says.
Blood product from cattle wins approval for use in humans

\section{Corie Lok}

An animal-derived blood substitute has been approved for use in humans in South Africa.

Hemopure, an oxygen-carrying compound derived from bovine haemoglobin, has been given the goahead for treating acute anaemia and for use during surgery.

Luc Noel, head of the World Health Organization's blood safety unit, says that treatment could be useful in South Africa's rural areas where safe blood is in short supply.

The World Health Organization estimates that one in five adult South Africans are infected with HIV. Noel says that he welcomes the new product if it reduces reliance on blood transfusions.

Hemopure was developed by Biopure of Cambridge, Massachusetts. The company says that the product is compatible with any blood type.

The raw haemoglobin used in Hemopure is harvested from US beef cattle bound for slaughter. Biopure requires the farmers to keep records of the cows' origin, feed, medical history and condition. The company says that its purification process removes infectious agents such as HIV, hepatitis $\mathrm{C}$ and transmissible spongiform encephalopathy agents.

Biopure says it will seek approval for Hemopure in the United States later this year, and then in Europe.

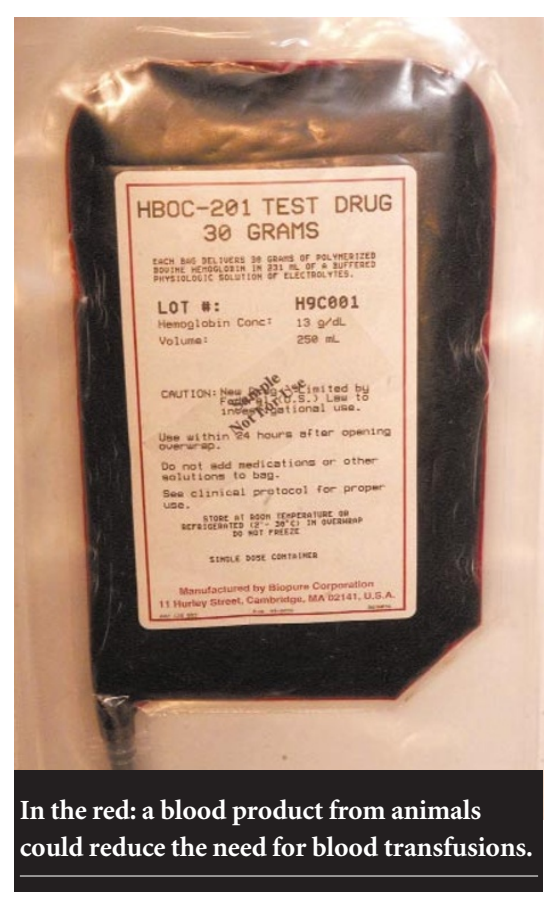

